\title{
Gender specific complications in female diabetic patients: an integrative view
}

\author{
Olga Golubnitschaja \\ From EPMA-World Congress 2013 \\ Brussels, Belgium. 20-21 September 2013
}

\section{Objective}

Current diabetes care is considered as insufficient regarding early diagnostics, targeted prevention and treatments tailored to the person. Further, gender specific diagnostics and treatment are not the issue of currently applied medical services in diabetes care. This is to understand status quo in diabetes complications and co-morbidities more typical for the female subpopulations.

\section{Material and methods}

Pubmed literature search within the years 1980-2013 [1].

\section{Results and interpretation}

Cardiovascular disease (CVD) is the best acknowledged complication in patients with Diabetes mellitus type 1 and type 2 . It has been well documented that female diabetics demonstrate poorer outcomes of CVD. A combination of the female gender and diabetes is the best recognised risk factor for high operation mortality by and low efficacy of the replacement of calcified valves [2]. Further, cardiovascular diseased women, in particular female diabetics, have poorer prognosis of oncologic diseases. The most frequent oncologic complications and co-morbidities in female diabetics are the following ones $[3,4]$ :

* endomentrium carcinoma (4.8-times higher prevalence in type 1 diabetes and 2.2-times higher in diabetes generally)

* ovarian carcinoma (2.42-times higher risk in female diabetics versus general female subpopulation)

* liver cancer (2.0-times higher risk)

* lymphoma (1.9-times higher risk)

* uterus carcinoma (1.7-times higher risk)
* rectum cancer (1.7-times higher risk)

* stomach cancer (1.6-times higher risk)

* leukaemia (1.4-times higher risk)

* kidney cancer (1.4-times higher risk)

* pancreatic cancer (1.3-times higher risk)

* breast cancer (1.2-times higher risk)

* lung cancer (1.1-times higher risk).

\section{Conclusions}

Common risk factors moderating the outcomes in the most frequent female pathologies, namely DM type 2, CVD and breast cancer are progressing age, overweight, poor diet, physical inactivity and depression. Modifiable risk factors persist from childhood and adolescence into adulthood and tend to cluster with synergistic negative effects for consequent manifestation of co-morbid pathologies [5]. However, there are significant knowledge deficits concerning "typical" versus "atypical" comorbidity profiles in diabetic females.

\section{Recommendations}

Although the coincidence is common in women, consistent data do not exist to recognise complications and co-morbid pathologies by patient profiling. Complications and complex clinical situations in elderly populations should be considered as the persistent challenge that requires new strategies in healthcare. Integrative medical approaches are strongly desirable to analyse common risk factors as well as their individual and synergistic effects. Frequent versus rare complication profiles in cardiovascular diseased patient cohorts should be created for advanced treatment regiments.

Published: 11 February 2014 


\section{References}

1. Golubnitschaja O: Changing Long-Held Beliefs Is Never Easy: A Proposal for Multimodal Approaches in Female Healhtcare - An Integrative View. In Healthcare Overview: New Perspectives. Springer;V. Costigliola 978-94-0074602-2 2012:, Book Series "Advances in Predictive, Preventive and Personalised Medicine" (Series Ed.: Golubnitschaja O).

2. Yeghiazaryan K, Skowasch D, Bauriedel G, Schild HH, Golubnitschaja O Prediction of Degeneration of Native and Bioprosthetic Aortic Valves. In Predictive diagnostics and personalized treatment: Dream or Reality. Nova Science Publishers, New York, USA;Golubnitschaja O 2009:

3. Inoue M, Iwasaki M, Otani T, Sasazuki S, Noda M, Tsugane S: Diabetes mellitus and the risk of cancer: results from a large-scale populationbased cohort study in Japan. Arch Intern Med 2006, 166:1871-1877.

4. Cebioglu M, Schild HH, Golubnitschaja O: Cancer predisposition in diabetics: risk factors considered for predictive diagnostics and targeted preventive measures. EPMA J 2010, 1(1):130-137, doi: 10.1007/s13167-0100015-4.

5. Pronk NP, Anderson LH, Crain AL, Martinson BC, O'Connor PJ, Sherwood NE, Whitebird RR: Meeting recommendations for multiple healthy lifestyle factors. Prevalence, clustering, and predictors among adolescent, adult, and senior health plan members. Am J Prev Med 2004, 27:25-33, doi:10.1016/j.amepre.2004.04.022.

doi:10.1186/1878-5085-5-S1-A78

Cite this article as: Golubnitschaja: Gender specific complications in female diabetic patients: an integrative view. EPMA Journal 2014 5(Suppl 1):A78.

\section{Submit your next manuscript to BioMed Central and take full advantage of:}

- Convenient online submission

- Thorough peer review

- No space constraints or color figure charges

- Immediate publication on acceptance

- Inclusion in PubMed, CAS, Scopus and Google Scholar

- Research which is freely available for redistribution

Submit your manuscript at www.biomedcentral.com/submit 